pISSN 2073-1477

Регион в наџиональной экономике

eISSN 2311-8733

МЕТОДИКА КОМПЛЕКСНОЙ ОЦЕНКИ РАЗВИТИЯ КОНКУРЕНЦИИ В РЕГИОНЕ

Виктория Викторовна БОБРОВА, ${ }^{\mathrm{a}, \bullet}$, Игорь Николаевич КОРАБЕЙНИКОВ Ольга Игоревна БАНТИКОВА

\author{
а доктор экономических наук, доцент, заведующая кафедрой таможенного дела, \\ Оренбургский государственный университет, Оренбург, Российская Федерация \\ bobrova1971@mail.ru \\ ${ }^{\mathrm{b}}$ кандидат экономических наук, доцент, заведующий кафедрой менеджмента, \\ Оренбургский государственный университет, Оренбург, Российская Федерация \\ igor.korabeynikov@mail.ru \\ c кандидат экономических наук, доцент кафедры математических методов и моделей в экономике, \\ Оренбургский государственный университет, Оренбург, Российская Федерация \\ bantikova777@mail.ru \\ - Ответственный автор
}

История статьи:

Получена 02.06.2017

Получена в доработанном виде 16.06.2017

Одобрена 26.06.2017

Доступна онлайн 15.09.2017

УДК 339.13 (470.56)

JEL: D41, L16, L19, R52, R58

Ключевые слова:

особенности,

конкурентоспособное развитие, социально значимые и приоритетные рынки, факторы, регион

\begin{abstract}
Аннотация
Предмет. Экономические, инвестиционные, организационные и иные отношения, возникающие в процессе развития конкуренции на социально значимых и приоритетных рынках региона.

Цели. Выявление региональных особенностей конкурентоспособного развития социально значимых и приоритетных рынков.

Методы. Основными методами работы стали социологическое исследование и количественная оценка полученных результатов. Проведение исследования осуществлено в соответствии со структурой пространственного и видового распределения экономических субъектов малого и среднего предпринимательства на региональном уровне.

Результаты. Предложена методика исследования оценки предпринимательским сообществом величины конкурентоспособного развития социально значимых рынков на основе комплексной оценки групп показателей по следующим направлениям исследования: характеристика бизнеса, оценка состояния конкуренции и конкурентной среды, оценка барьеров ведения предпринимательской деятельности. Определено, что спецификой авторской методики является комплексное изучение мнения представителей малого и среднего бизнеса региона об изменении условий конкурентоспособного развития социально значимых и приоритетных рынков на основе количественной оценки. Представлены особенности и факторы конкурентоспособного развития социально значимых и приоритетных рынков на региональном уровне. Предложены детерминанты и условия конкурентоспособного развития социально значимых рынков на мезоуровне. Показано, что к региональным особенностям конкурентоспособного развития социально значимых рынков относятся наличие дифференцированных административных барьеров входа на рынки, недостаточное развитие институтов предпринимательства, проблемы в отношениях с естественными монополиями, недостаточная информированность предпринимательского сообщества о возможностях ведения бизнеса и ряд других.

Выводы. На основании предложенной методики и проведенных социологических исследований были выделены факторы, которые, по мнению населения и бизнеса региона, оказывают как положительное, так и отрицательное влияние на развитие конкуренции на социально значимых и приоритетных рынках. Материалы статьи могут быть полезны специалистам, занимающимся проблемами конкурентоспособного развития мезоэкономических рыночных систем.
\end{abstract}

(С Издательский дом ФИНАНСЫ и КРЕДИТ, 2017

Для цитирования: Боброва В.В., Корабейников И.Н., Бантикова О.И. Методика комплексной оценки развития конкуренции в регионе // Региональная экономика: теория и практика. - 2017. - Т. 15, № 9. - С. 1598 - 1614. https://doi.org/10.24891/re.15.9.1598 


\section{Конкурентная}

ключевым инструментом основных направлений

экономического развития включая формирование институциональной среды для инновационного развития, снижение инфляции, создание условий для повышения качества и уровня жизни населения, развитие конкурентоспособности региональной экономики в целом.

Теоретические основы конкуренции освещены в работах Т.А. Завьяловой, А. Маршалла, P.А. Фатхутдинова, В.И. Харламова, М. Портера [1-5].

Основным инструментом стимулирования развития конкуренции в Российской Федерации должна стать реализация мероприятий («дорожной карты») «Развитие конкуренции и совершенствование антимонопольной политики». В целях оказания методологической помощи регионам в создании конкурентной среды в сентябре 2015 г. был принят Стандарт развития конкуренции в субъектах Российской Федерации, разработанный в целях совершенствования конкурентной политики. В настоящее время большое внимание к развитию конкурентной среды в субъектах Российской Федерации вызвано тем, что данный показатель включен в Перечень показателей оценки эффективности деятельности высших должностных лиц (руководителей высших исполнительных органов государственной власти) субъектов Российской Федерации по созданию благоприятных условий ведения предпринимательской деятельности, утвержденный распоряжением Правительства Российской Федерации от 10.042014 № 570-p. Исключительно высокая неоднородность экономического пространства регионов является признанной особенностью современной российской экономики. В этой связи одной

\footnotetext{
*Авторы выражают благодарность и признательность заместителю министра - начальнику управления экономики и макроэкономического прогнозирования Министерства экономического развития, промышленной политики и торговли Оренбургской области кандидату экономических наук Елене Сергеевне ЗДОРОВОЙ за советы и ценные замечания при работе над статьей. Статья подготовлена при финансовой поддержке областного гранта, соглашение от 30.06.2016 № 30 .
}

из наиболее заметных тенденций является усиление соперничества и состязательности экономических субъектов внутри территорий (регионов и муниципальных образований), то есть процессы внутри региональной конкуренции.

Регулирование региональными и местными органами власти механизмов конкурентной борьбы становится объективно необходимым и является катализатором активизации потенциала территории, дополнительным фактором обеспечения устойчивого и стратегически ориентированного территориального развития. В качестве универсальной синтетической характеристики результативности функционирования территории выступает степень развития конкурентоспособности ${ }^{1}$.

Социально-экономические и производственнотехнологические позиции региона зависят от конкуренции на внутренних рынках не только его ведущих народнохозяйственных ресурсов, основных кластеров и предприятий, но и от возможности обеспечить такое развитие инвестиционными ресурсами. Поэтому в качестве важнейшего аспекта развития конкуренции на территории следует рассматривать сравнительную привлекательность для производителей и наличие условий для развития производства, которые в значительной мере «овеществляются» в форме основного капитала, как считают И.В. Богомолова, Л.С. Машенцова и Н.А. Гринева [6, 7].

В связи с тем что в настоящее время отсутствует единый методологический подход к количественной оценке конкурентоспособности региона, нами была разработана методика оценки конкурентоспособности на примере Оренбургской области.

Обзор методик оценки развития региональных социально-экономических систем представлен в работах Е.Л. Дугиной

\footnotetext{
${ }^{1}$ Бережная Е.В. Понятие конкурентного преимущества региона, сравнительный анализ методик оценки

конкурентоспособности регионов // Актуальные проблемы современной науки: сборник трудов конференции. Ставрополь: Ставропольский университет, 2012. Т. 1. Вып. 1. С. 46-49.
} В.В. Боброва и др. / Региональная экономика: теория и практика, 2017, т. 15, вып. 9, стр. 1598-1614 
и Д.В. Битуевой, В.В. Смирнова, В.В. Худеевой, Э.Л. Пашнанова, Е.Ф. Прокушева и Н.А. Гриневой, Е.В. Соповой и Л.Ю. Щербининой, Г.Л. Азоева [8-14] $]^{2}$.

Развитию конкуренции в регионе способствуют мероприятия, реализуемые министерством экономического развития, промышленной политики и торговли Оренбургской области и другими исполнительными органами государственной власти в рамках региональной «дорожной карты». Структурные показатели конкурентной среды свидетельствуют о значительном потенциале развития конкуренции в регионе.

Формирование перечня социально значимых и приоритетных рынков в области необходимо проводить, опираясь на соответствующее методическое обеспечение. Принципиальные положения подходов к разработке перечня социально значимых и приоритетных рынков в регионе обоснованы в Стандарте развития конкуренции в субъектах Российской Федерации ${ }^{3}$.

В соответствии со Стандартом нами были использованы некоторые положения:

- во-первых, при формировании перечня приоритетных рынков в первую очередь включать в него следует рынки, которые характеризуются наличием значимых проблем, препятствующих конкуренции;

- во-вторых, в перечень необходимо включать рынки товаров, работ и услуг несырьевого сектора экономики с высокой степенью передела и добавленной стоимости конечной продукции, имеющей экспортный потенциал и (или) возможность замещения импорта, чьи производственно-технологические и инновационные цепочки, а также цепочки создания добавленных стоимостей находятся преимущественно

\footnotetext{
${ }^{2}$ Шеховцева Л.С. Обоснование методики конкурентоспособности российских регионов // Региональная экономика: теория и практика. 2007. № 6. С. 31-37.

${ }^{3}$ Стандарт развития конкуренции в субъектах Российской Федерации. URL: http://fas.gov.ru/vazhnaya-informacziya/standartrazvitiya-konkurenczii//
}

в Российской Федерации (в том числе в рамках промышленных и инновационных кластеров);

- в-третьих, особое внимание при формировании перечня приоритетных рынков заслуживает уровень производств высокотехнологичной продукции и (или) технически сложной продукции с перспективными технологиями, стремящимися к инновационным системам полного цикла в Российской Федерации и имеющими потенциал достижения новых технологических уровней и (или) потенциал встраивания в глобальную производственную и технологическую кооперацию.

По нашему мнению, необходимо осуществлять формирование перечня рынков на основе результатов ежегодного мониторинга, с внесением определенных корректив.

По мнению Н.В. Ялиной [15], при формировании перечня социально значимых рынков опираться следует на обязательный перечень, предусмотренный приложением к стандарту, в отношении которых целесообразно придерживаться установленных числовых значений целевых показателей либо установить числовые значения целевых показателей с учетом региональной специфики.

В качестве информационной базы для формирования перечня рынков выступают:

- сведения территориальных и федеральных органов исполнительной власти, в том числе территориального органа Федеральной антимонопольной службы, полученные в результате анализа товарных рынков субъекта Российской Федерации и в результате проведения антимонопольного контроля;

- показатели социально-экономического развития субъекта Российской Федерации (включая показатели по каждому из отдельных муниципальных образований);

- инвестиционные приоритеты, определенные документом стратегического 
планирования в области инвестиционной деятельности (инвестиционной стратегии) субъекта Российской Федерации;

- инв естиционны е механизмы и приоритеты, определенные документом стратегического планирования в области инвестиционной деятельности муниципальных образований, при формировании которого предусматривается ознакомление органов местного самоуправления с информационными материалами, обобщающими лучшие муниципальные практики («Атлас муниципальных практик»), разработанными автономной некоммерческой организацией «Агентство стратегических инициатив по продвижению новых проектов», которые в случае необходимости можно использовать в работе;

- сведения, содержащиеся в документах стратегического планирования Российской Федерации, субъекта Федерации и муниципальных образований (при наличии);

- результаты аналитических исследований и опросов субъектов предпринимательской деятельности, экспертов, потребителей товаров, работ и услуг и общественных организаций, представляющих интересы потребителей, включая результаты мониторинга;

- информация научных, исследовательских, аналитических и проектных организаций, экспертные оценки состояния рынков и отраслей региональной экономики, а также данные хозяйствующих субъектов об их деятельности;

- положения и принципы Стандарта развития конкуренции в субъектах Российской Федерации;

- положительный опыт и практика других регионов Российской Федерации;

- транспарентность механизмов выделения социально значимых и приоритетных рынков в регионе;

- данные социальной экспертизы предложений по выделению социально значимых и приоритетных рынков в регионе;

- обеспечение комплексного стабильного положения региона и перспектив развития;

- системность в реализации подходов к выделению социально значимых и приоритетных рынков в регионе;

- инвестиционный рейтинг региона;

- сведения о развитии региональной системы материального и нематериального производства товаров и услуг;

- данные о качестве предоставляемых населению товаров и услуг и др.

Систематизация методических принципов, представленных в работах Е.Ф. Прокушева и Н.А. Гриневой [12], Т.П. Данько и Е.В. Заровой [16], А.И. Кагармановой [17] позволила нам разработать методику определения перечня социально значимых и приоритетных рынков в регионе, которая включает проведение процедур, представленных в табл. 1.

На основании предложенной методики в качестве основных принципов выделения социально значимых рынков нами были обозначены [9]:

- высокая социальная значимость выделенных рынков;

- значительное влияние выделенных рынков на социальную стабильность в регионе;

- ориентация организаций рынков на решение социальных проблем, возникающих в регионе;

- уменьшение социальной напряженности в регионе посредством обеспечения реализации базовых потребностей населения;

- ориентация организаций социально значимых рынков на реализацию федеральных и региональных приоритетов социально ориентированного развития; 
- значительное представительство организаций социально значимых рынков в муниципальных образованиях региона и др ${ }^{4}$.

В соответствии с данными принципами и учитывая региональную специфику Оренбургской области, были выделены следующие социально значимые рынки:

- услуг дошкольного образования;

- услуг детского отдыха и оздоровления;

- услуг дополнительного образования детей;

- медицинских услуг;

- услуг психолого-педагогического сопровождения детей с ограниченными возможностями здоровья;

- услуг в сфере культуры;

- услуг жилищно-коммунального хозяйства;

- розничной торговли;

- услуг перевозок пассажиров наземным транспортом;

- услуг связи;

- услуг социального обслуживания населения.

Выделение приоритетных рынков, по нашему мнению, следует проводить, полагаясь на следующие принципы [9]:

- приоритетности развития экономики региона в целом относительно развития экономических субъектов;

- формирования системы импортозамещения в регионе;

- ориентации на объективно сложившиеся предпосылки в развитии рынков производителей, потребителей, посредников;

- ограниченности в выделении приоритетных рынков;

- возможности органов государственной власти регулировать развитие приоритетных рынков;

\footnotetext{
${ }^{4}$ Стандарт развития конкуренции в субъектах Российской Федерации. URL: http://fas.gov.ru/vazhnaya-informacziya/standartrazvitiya-konkurenczii
}

В.В. Боброва и др. / Региональная экономика: теория и практика, 2017, т. 15, вып. 9, стр. 1598-1614
- управляемости развития приоритетных рынков;

- согласованности развития приоритетных рынков со стратегическими направлениями развития региона и др..

В соответствии с данными принципами и принятой стратегией развития Оренбургской области были обозначены следующие приоритетные рынки:

- выращивания овощей в закрытом грунте;

- хранения овощей;

- хранения зерна;

- услуг по перевозке пассажиров автомобильным транспортом, подчиняющимся расписанию, в муниципальных образованиях.

Для обоснования принципов выделения социально значимых и приоритетных рынков в Оренбургской области нами был осуществлен мониторинг состояния и развития конкурентной среды, в рамках которого проведены опросы представителей предпринимательского сообщества и жителей области по вопросам оценки условий ведения бизнеса, административных барьеров, затрудняющих предпринимательскую деятельность, эффективности мер поддержки предпринимательства, а также удовлетворенности уровнем развития конкурентной среды в регионе.

Опросы в форме анкетирования были проведены во всех муниципальных районах и городах области, при этом общий объем выборки составил 2472 респондента, из них 1128 - субъекты предпринимательской деятельности, 1344 - потребители товаров и услуг.

Мониторинг проводился на рынках 22 основных для экономики области сфер предпринимательской деятельности и 20 рынках товаров, работ и услуг, которые оценивали потребители. Согласно результатам исследований предпринимательское

\footnotetext{
${ }^{5}$ Стандарт развития конкуренции в субъектах Российской Федерации. URL: http://fas.gov.ru/vazhnaya-informacziya/standartrazvitiya-konkurenczii/
} 
сообщество в целом удовлетворено общими условиями ведения бизнеса в Оренбургской области ${ }^{6}$.

В числе положительных тенденций отмечены:

- повышение количества конкурентов на большинстве рынков товаров и услуг;

- поддержка субъектов малого и среднего бизнеса со стороны органов власти;

- положительная оценка деятельности субъектов естественных монополий на территории Оренбургской области;

- отсутствие существенных барьеров для ведения бизнеса (даже имеющиеся административные барьеры в виде высоких налогов и нестабильности российского законодательства, регулирующего предпринимательскую деятельность, по мнению опрошенных предпринимателей, достаточно легко преодолимы).

Положительно оценивается деятельность исполнительных органов власти и Федеральной антимонопольной службы по Оренбургской области, направленная на снижение уровня административных барьеров, а также информационная поддержка со стороны органов власти.

К основным административным барьерам для ведения текущей деятельности или открытия нового бизнеса на рынке субъекты предпринимательской деятельности отнесли:

- высокие налоги;

- нестабильность российского законодательства, регулирующего предпринимательскую деятельность.

- При этом 22\% от всех опрошенных вовсе не видят никаких административных

\footnotetext{
${ }^{6}$ Боброва В.В., Окшин В.В., Корабейников И.Н., Бантикова О.И., Корабейникова О.А., Полякова И.Л., Попов В.В., Рожкова Ю.В., Савина А.М., Холодилина Ю.Е. Разработка теоретико-методических основ развития конкуренции в Оренбургской области / Информационная карта по отчету о НИР. Регистрационный номер НИОКТР

AAAA-A16-116070410131-7. Регистрационный номер ИКРБС АААА-Б17-217022840034-5. Оренбург: ОГУ, 2017. 260 с.
}

барьеров для осуществления текущей деятельности.

Положительное влияние на развитие конкуренции на рынке товаров и услуг оказывает деятельность исполнительных органов власти Оренбургской области и Федеральной антимонопольной службы, направленная на снижение уровня административных барьеров.

В результате опроса субъектов предпринимательства о состоянии конкурентной среды на рынке товаров и услуг определено, что основная часть предпринимателей, принявших участие в опросе, охарактеризовала деятельность органов власти на основном рынке их бизнеса как положительную. Более $38 \%$ респондентов считают, что власти помогают бизнесу своими действиями, 18\% опрошенных считают, что в чем-то органы власти помогают, в чем-то мешают, $11 \%$ придерживаются точки зрения, что органы власти ничего не предпринимают для поддержки.

Оценивая преодолимость административных барьеров для ведения текущей деятельности и открытия нового бизнеса, $28 \%$ опрошенных убеждены в отсутствии административных барьеров; 25\% считают, что административные барьеры есть, но они преодолимы без существенных затрат.

Большая часть опрошенных предпринимателей отмечает, что бизнесу стало проще преодолевать административные барьеры, чем раньше на рынках:

\section{- здравоохранения и предоставления социальных услуг;}

- текстильного и швейного производства;

- гостиничного и ресторанного бизнеса.

Большинство опрошенных респондентов указало на отсутствие существенных и непреодолимых административных барьеров на рынке производства и распределения электроэнергии, газа 
и воды, а также на рынке предоставления коммунальных услуг.

В то же время существует ряд барьеров, затрудняющих деятельность хозяйствующих субъектов на данных рынках. Среди них особо выделяют:

- сложность получения доступа к земельным участкам;

- нестабильность российского законодательства, регулирующего п предпринимательскую деятельность;

- сложность/затянутость процедуры получения лицензий, разрешений;

- высокие налоги.

На основании проведенного опроса выявлено, что более половины предпринимателей в своей деятельности периодически пользуются официальной информацией, что свидетельствует о ее востребованности.

Качество официальной информации о состоянии конкурентной среды на рынках товаров и услуг Оренбургской области, размещенной в открытом доступе, более половины респондентов оценили как удовлетворительное ${ }^{7}$ :

- по уровню доступности - 38\%;

- по уровню понятности - 35\%;

- по удобству получения - 33\%.

В процессе анализа полученных ответов было выявлено, что одни рынки отличаются достаточно активной информационностью (рынок услуг перевозок пассажиров наземным транспортом), другие недостаточно используют официальную информацию (рынок выращивания (в закрытом грунте) и хранения овощей).

\footnotetext{
${ }^{7}$ Боброва В.В., Окшин В.В., Корабейников И.Н., Бантикова О.И., Корабейникова О.А., Полякова И.Л., Попов В.В., Рожкова Ю.В., Савина А.М., Холодилина Ю.Е. Разработка теоретико-методических основ развития конкуренции в Оренбургской области / Информационная карта по отчету о НИР. Регистрационный номер НИОКТР

АААА-А16-116070410131-7. Регистрационный номер ИКРБС АААА-Б17-217022840034-5. Оренбург: ОГУ, 2017. 260 с.
}

При этом наиболее востребованной является официальная информация органов власти. Что касается телевидения и печатных СМИ, то информация, полученная из этих источников, иногда подвергается сомнению. Отсюда следует, что к выбору канала размещения информации необходимо подходить предельно внимательно и разборчиво. Следует обратить внимание и на достаточно высокую долю опрошенных потребителей, которым ничего не известно о такой информации.

В ходе мониторинга состояния и развития конкурентной среды нами был проведен анализ существующего уровня конкуренции на различных рынках товаров и услуг Оренбургской области, который показал, что очень высокая конкуренция отмечается на рынках розничной торговли, производства пищевых продуктов (включая напитки) и табака, а также транспорта и связи.

Высокая конкуренция, по мнению опрашиваемых предпринимателей, наблюдается в строительстве, торговле автотранспортными средствами и мотоциклами, их обслуживании и ремонте, a также при производстве готовых металлических изделий. Предприниматели отмечают, что количество конкурентов во всех перечисленных сферах за последние три года увеличилось.

Положительной тенденцией является рост количества конкурентов на большинстве рынков товаров и услуг. Однако несмотря на увеличение субъектов предпринимательства, проблемными, с точки зрения развития конкуренции, в Оренбургской области остаются такие социально значимые рынки, как здравоохранение и предоставление социальных услуг, характеризующиеся недостаточной конкуренцией.

Представители гостиничного и ресторанного бизнеса при низкой конкуренции отмечают тем не менее рост конкурентов за последние три года. 
Отсутствие конкуренции, по мнению опрашиваемых субъектов предпринимательской деятельности, отмечается:

- на рынке производства и распределения электроэнергии, газа и воды;

- на рынке предоставления жилищнокоммунальных услуг.

Высокая конкуренция на рынке товаров и услуг стимулирует предпринимателей для сохранения рыночной позиции регулярно (раз в год или чаще) предпринимать меры по повышению конкурентоспособности продукции, использовать инновационные подходы, обеспечивающие повышение удовлетворенности клиентов и рост операционной эффективности.

На рынках с низким уровнем конкуренции, хозяйствующим субъектам нет необходимости предпринимать какие-либо меры, что приводит к низкой удовлетворенности потребителей уровнем цен и качеством товаров и услуг.

Однако доминирование государственных (муниципальных) организаций и регулирование тарифов на ряде неконкурентоспособных рынков позволяет достичь достаточно высокой удовлетворенности потребителей уровнем цен, но существенно тормозит увеличение количества субъектов предпринимательства и снижает уровень удовлетворенности потребителей количеством и разнообразием предоставляемых услуг.

Лидирующие позиции по уровню удовлетворенности потребителей качеством товаров, работ, услуг и состоянием цен является рынок услуг связи, за ним следует рынок розничной торговли, а замыкает тройку лидеров рынок услуг перевозок пассажиров наземным транспортом.

Настораживает сравнительно низкая позиция рынка туристических и рекреационных услуг, услуг детского отдыха и оздоровления, а также медицинских услуг, что связано с малым количеством организаций данных рынков и завышенными ценами. При этом качество, в частности, медицинских услуг, по мнению опрашиваемых респондентов, оставляет желать лучшего. Именно на эти рынки необходимо обратить внимание при разработке плана мероприятий по содействию развитию конкуренции.

На рынках производства и распределения электроэнергии, газа и воды и предоставления коммунальных услуг, по мнению опрашиваемых представителей бизнеса, вовсе отсутствует конкуренция.

По мнению потребителей, цены в Оренбургской области выше по сравнению с другими регионами на рынке жилищно-коммунальных услуг (такого мнения придерживаются 14\% опрошенных респондентов), на рынке розничной торговли (13\%), на рынке медицинских услуг $(12 \%)^{8}$. На всех остальных рынках, за исключением рынка культуры, большинство опрошенных потребителей отметили увеличение цен в течение последних трех лет, при этом качество и возможность выбора товаров и услуг осталось на неизменном уровне.

Цены и качество на рынке культуры, по мнению большинства опрошенных потребителей, не изменились на протяжении последних трех лет. Что касается критериев, выделяемых респондентами, при приобретении того или иного товара (услуги), то по-прежнему доминирует цена, на втором месте отмечено «мнение друзей, знакомых, родственников», на третьем - «производитель».

Ответы респондентов относительно оценки услуг субъектов естественных монополий в Оренбургской области по срокам получения доступа, показали, что большинство опрошенных удовлетворительно оценили услуги телефонной связи, скорее удовлетворительно - услуги водоснабжения,

\footnotetext{
${ }^{8}$ Боброва В.В., Окшин В.В., Корабейников И.Н., Бантикова О.И., Корабейникова О.А., Полякова И.Л., Попов В.В., Рожкова Ю.В., Савина А.М., Холодилина Ю.Е. Разработка теоретикометодических основ развития конкуренции в Оренбургской области / Информационная карта по отчету о НИР. Регистрационный номер НИОКТР АААА-А16-116070410131-7. Регистрационный номер ИКРБС АААА-Б17-217022840034-5. Оренбург: ОГУ, 2017. 260 с.
} 
водоотведения, газоснабжения , электроснабжения и теплоснабжения.

Болышинство опрошенных по критерию сложности п процедур подключения удовлетворительно оценили услуги водоснабжения, водоотведения, газоснабжения, электроснабжения, теплоснабжения и телефонной связи.

Стоимость подключения услуг водоснабжения и водоотведения большинство опрошенных предпринимателей считают скорее низкой, а услуг газоснабжения, по мнению $24 \%$ опрошенных предпринимателей, наоборот, завышенной.

Стоимость подключения услуг энергоснабжения и теплоснабжения оценили как «скорее высокую», а услуг телефонной связи 20\% опрошенных считают скорее низкой.

Анализ результатов оценки качества услуг субъектов естественных монополий, позволяет сделать вывод, что опрошенные потребители наиболее удовлетворены услугами г газоснабжения, электроснабжения, теплоснабжения и телефонной связи. В меньшей степени опрошенные респонденты удовлетворены услугами водоснабжения, водоотведения, а также водоочистки.

По результатам проведенного социологического опроса нами были определены основные векторы развития конкуренции в Оренбургской области, состоящие из системных мероприятий и мероприятий развития приоритетных и социально значимых рынков.

K системным мероприятиям следует отнести:

- оптимизацию мониторинга состояния и развития конкурентной среды на рынках товаров и услуг Оренбургской области;

- оптимизацию процедур государственных закупок посредством применения конкурсных процедур и проведения централизованных закупок;
- устранение

и збы т очн о г государственного регулирования и снижение административных барьеров;

- привлечение органов местного самоуправления к внедрению Стандарта развития конкуренции;

- повышение уровня информированности субъектов предпринимательской деятельности и потребителей товаров и услуг о состоянии конкурентной среды и деятельности по содействию ее развития в области посредством размещения информации в сети Интернет на сайтах правительства и министерства экономического развития, промышленной политики и торговли Оренбургской области, а также Управления Федеральной антимонопольной службы по Оренбургской области.

В качестве основных направлений развития приоритетных и социально значимых рынков Оренбургской области можно назвать:

- снижение или устранение правовых, административных, финансовых барьеров для хозяйствующих субъектов;

- повышение уровня информационной открытости деятельности органов исполнительной власти Оренбургской области.

Важным мероприятием «дорожной карты» является организация мониторингов состояния и развития конкурентной среды на рынках товаров и услуг области, на основе которых планируется актуализация «дорожной карты».

Это позволит выстроить прозрачную систему действий региональных органов государственной власти в части реализации эффективных мер по развитию конкуренции в интересах потребителей товаров и услуг и субъектов предпринимательской деятельности.

Развитие конкуренции в настоящее время находится в фокусе внимания государства, так как конкуренция является одним из 
факторов экономического роста. Местные органы власти должны уделять больше внимания организации процесса демонополизации и развития конкуренции.

Общепринятые представления о мерах развития конкуренции включают в себя следующие направления деятельности:

- увеличение количества хозяйствующих субъектов, предпринимателей;

- борьбу с монополистами, то есть развитие конкурентных отношений в монополизированных отраслях экономики;

- стимулирование повышения качества продаваемой продукции, контроль за качеством;

- внедрение конкурсных способов заключения договоров;

- оптимизацию механизма предоставления государственной и муниципальной помощи.

Отдельным важным инструментом развития конкуренции является введение конкурсной системы закупок. Предприниматели отмечают ряд недостатков в настоящей системе:

- ориентацию на стоимость товара, а не на его качество;

- формальность критериев оценки качества;

- предельную оптимизацию сметы закупки, не позволяющую приобрести товар по среднерыночной себестоимости.

Признавая ведущую роль государства в вопросе развития конкуренции, предприниматели не желают оставаться вне этого процесса и выдвигают требования на равноправный диалог с властью.

Одним из перспективных инструментов развития конкуренции может быть стимулирование создания/развития новых рынков. При этом может произойти смещение акцентов с роста объемов контроля за конкуренцией на создание условий для роста бизнеса и конкуренции.

Если говорить о социально значимых рынках для содействия развитию конкуренции в Оренбургской области, то следует упомянуть рынок услуг дошкольного образования. Необходимо поддерживать участников данного рынка, сохраняя разнообразие предложений, увеличивая количество участников рынка. Сокращение предложений ведет к потере ценных трудовых ресурсов, как считают В.В. Боброва, В.В. Окшин, И.Н. Корабейников и др.

Социальная значимость рынка медицинских услуг не подлежит сомнению. Для развития конкуренции необходимо восстановить количество «игроков». Наблюдается монополизация данного рынка, a это может привести к снижению качества и объемов медицинских услуг.

Рынок розничной торговли привлекает внимание экспертов. Основными задачами здесь являются активный запуск процесса демонополизации, сохранение мелких «игроков». Важно создание условий для возникновения альянсов, торговых объединений, агрохолдингов, мелких розничных предпринимателей, что позволит им противостоять крупным торговым сетям. Органам власти в рамках развития конкуренции следует включить в перечень мероприятия по созданию условий для частной торговли продуктами подсобного хозяйства на рынках выходного дня или специально закрепленных и оборудованных местах на рынках города и области. В продолжение этой идеи население хотело бы получать больше информации о регулярности проведения таких ярмарок и участвовать в их работе как в качестве покупателей, так и продавцов.

Рынок услуг перевозок пассажиров автомобильным транспортом на межмуниципальных маршрутах Оренбургской области нуждается 
в развитии конкуренции. Отмечается, что схема работы данного рынка не исключает возникновения и развития коррупционных cхем.

Рынок услуг дошкольного образования, детского отдыха и оздоровления, дополнительного образования детей испытывает дефицит кадровых ресурсов. Особенно это касается узких специалистовпрофессионалов. Появление и развитие новых хозяйствующих субъектов на этих рынках возможно только при положительной динамике кадровой ситуации.

Рынок жилищно-коммунального хозяйства отличается высокой степенью монополизации. В связи с этим необходимы мероприятия по увеличению количества участников этого рынка, расширению списка исполнителей.

Рынок услуг перевозок пассажиров наземным транспортом характеризуется наличием серьезных входных барьеров (техническое обеспечение, наличие ремонтной базы, наличие постоянного штата), что является условием монополизации. Для развития конкуренции на данном рынке со стороны государства можно создать необходимую инфраструктуру (например, государственную ремонтную базу, услуги специалистов по обслуживанию транспорта), которая позволит увеличить количество сертифицированных участников рынка.

Целесообразно в «дорожной карте» предусмотреть комплекс мероприятий, связанных с импортозамещением и предоставлением мер поддержки именно местным производителям.

По результатам социологического исследования нами был переработан план мероприятий («дорожная карта») по содействию развитию конкуренции в регионе, который определяет перспективные показатели развития социально значимых и приоритетных рынков, а также выработку мероприятий регионального уровня, которые будут ориентированы как на развитие самих рынков, так и направлены на развитие конкурентной среды в Оренбургской области. 
Таблица 1

Методика определения перечня социально значимых и приоритетных рынков в регионе

Table 1

Methodology for the identification of a list of socially significant and priority markets in the region

\begin{tabular}{|c|c|c|}
\hline $\begin{array}{c}\text { № } \\
\text { ПI/II }\end{array}$ & Этап & Содержание этапа \\
\hline \multicolumn{3}{|c|}{$\begin{array}{c}\text { 1. Обоснование макроэкономических и мезоэкономических предпосылок } \\
\text { развития социально значимых и приоритетных рынков }\end{array}$} \\
\hline 1.1 & $\begin{array}{l}\text { Выделение нормативно-правовых основ } \\
\text { развития социально значимых и } \\
\text { приоритетных рынков }\end{array}$ & $\begin{array}{l}\text { Классификация перечня нормативных правовых актов } \\
\text { федерального и регионального уровня, регламентирующих } \\
\text { социально значимые процессы и перспективные направления } \\
\text { мезоэкономического развития }\end{array}$ \\
\hline 1.2 & $\begin{array}{l}\text { Адаптация принципов Стандарта развития } \\
\text { конкуренции в субъектах Российской } \\
\text { Федерации к региональным условиям } \\
\text { хозяйствования }\end{array}$ & $\begin{array}{l}\text { Уточнение аспектов и принципов использования положений } \\
\text { Стандарта развития конкуренции в субъектах Российской } \\
\text { Федерации с учетом особенностей и условий на территории } \\
\text { региона }\end{array}$ \\
\hline 1.3 & $\begin{array}{l}\text { Классификация положительных российских } \\
\text { практик выделения и развития социально } \\
\text { значимых и приоритетных рынков }\end{array}$ & $\begin{array}{l}\text { Выделение перечня положительных российских практик } \\
\text { выделения и развития социально значимых и приоритетных } \\
\text { рынков с определением возможностей их использования } \\
\text { в регионе на основе повышения результативности } \\
\text { регионального развития }\end{array}$ \\
\hline \multicolumn{3}{|c|}{ 2. Обоснование перечня социально значимых рынков } \\
\hline 2.1 & $\begin{array}{l}\text { Формулирование социальных проблем, } \\
\text { существующих в регионе }\end{array}$ & $\begin{array}{l}\text { Обоснование и прогнозирование проблем и направлений, } \\
\text { которые могут привести к дестабилизации социальной } \\
\text { ситуации в регионе. Определение перспективных планов } \\
\text { повышения стабильности социальной ситуации в регионе }\end{array}$ \\
\hline 2.2 & $\begin{array}{l}\text { Адаптация перечня рекомендованных } \\
\text { социально значимых рынков } \\
\text { под региональные условия }\end{array}$ & $\begin{array}{l}\text { Определение рекомендованного перечня социально } \\
\text { значимых рынков. Формулирование возможности и } \\
\text { перспектив использования данного перечня в регионе }\end{array}$ \\
\hline 2.3 & $\begin{array}{l}\text { Формулирование перечня социально } \\
\text { значимых рынков }\end{array}$ & $\begin{array}{l}\text { Формализация перечня социально значимых рынков } \\
\text { на мезоэкономическом уровне }\end{array}$ \\
\hline \multicolumn{3}{|c|}{ 3. Обоснование перечня приоритетных рынков } \\
\hline 3.1 & $\begin{array}{l}\text { Формулирование приоритетных } \\
\text { направлений перспективного развития } \\
\text { региона и отдельных рынков }\end{array}$ & $\begin{array}{l}\text { Обоснование и прогнозирование приоритетных направлений } \\
\text { развития региона. Определение перспективных планов } \\
\text { повышения стабильности производственно-экономической } \\
\text { ситуации в регионе }\end{array}$ \\
\hline 3.2 & $\begin{array}{l}\text { Оценка перечней приоритетных рынков } \\
\text { по регионам Российской Федерации } \\
\text { и формулирование позиции региона } \\
\text { по возможности конкурентного развития }\end{array}$ & $\begin{array}{l}\text { Определение рекомендованного перечня социально } \\
\text { значимых рынков. Формулирование возможности и } \\
\text { перспектив использования данного перечня в регионе }\end{array}$ \\
\hline 3.3 & $\begin{array}{l}\text { Формулирование перечня приоритетных } \\
\text { рынков }\end{array}$ & $\begin{array}{l}\text { Формализация перечня приоритетных рынков } \\
\text { на мезоэкономическом уровне }\end{array}$ \\
\hline
\end{tabular}

Источник: авторская разработка

Source: Authoring 


\section{Список литературы}

1. Завьялова Т.А. Конкурентоспособность экономики: от оценки к методике // Креативная экономика. 2011. № 9. C. 10-15. URL:

https://cyberleninka.ru/article/n/konkurentosposobnost-ekonomiki-ot-otsenki-k-metodike

2. Маршалл А. Принципы политической экономии. М.: Прогресс, 1983. 416 с.

3. Фатхутдинов Р.А. Концепция новой теории управления конкурентоспособностью и конкуренцией // Современная конкуренция. 2007. № 1. С. 73-86.

4. Харламов В.И. О многоаспектности трактовки категории «конкуренция» // Вестник Белгородского университета кооперации, экономики и права. 2005. № 5. С. 125-129.

5. Портер М. Международная конкуренция: конкретные преимущества стран. М.: Международные отношения, 1993. 896 с.

6. Богомолова И.В., Машенцова Л.С. Развитие методики оценки конкурентоспособности городов по количественным и качественным параметрам // Вестник Волгоградского государственного университета. Сер. 3. Экономика. Экология. 2015. № 3. С. 20-26. doi: 10.15688/jvolsu3.2015.3.2

7. Гринева Н.А. Методика оценки конкурентоспособности региональной экономики // Научные ведомости БелГУ. Сер. Экономика. Информатика. 2010. № 13. Вып. 15/1. C. $15-22$.

8. Дугина Е.Л., Битуева Д.В. и др. Формирование и развитие конкурентоспособной системы отраслевых рынков региона: коллективная монография. Улан-Удэ: ВСГУТУ, 2015. $216 \mathrm{c}$.

9. Смирнов B.B. Методика оценки конкурентоспособности региона: теория и практика // Вестник Чувашского университета. 2008. № 3. С. 470-480.

10. Худеева B.B. О подходах к оценке конкурентоспособности региона в условиях модернизации федеральной политики регионального развития: методика оценки // Вестник Челябинского государственного университета. 2011. № 32. С. 60-64.

11. Пашнанов Э.Л. Методика оценки развития региональных социально-экономических систем // Управление экономическими системами: электроннный научный журнал. 2012. № 6. C. 14. URL: https://cyberleninka.ru/article/n/metodika-otsenki-razvitiyaregionalnyh-sotsialno-ekonomicheskih-sistem-1

12. Прокушев Е.Ф., Гринева Н.А. Обзор современных отечественных методик оценки конкурентоспособности региона и необходимость их разработки с учетом трудовых ресурсов // Вестник Белгородского университета кооперации, экономики и права. 2015. № 3. C. 86-95.

13. Сопова Е.В., Щербинина Л.Ю. Обзор методик по оценке уровня конкуренции на рынке // Вопросы экономики и управления. 2016. № 3-1. С. 47-49.

14. Азоев Г.Л. Конкуренция: анализ, стратегия и практика: монография. М.: Центр экономики и маркетинга, 1996. 208 с.

15. Ялина Н.В. Методика оценки конкурентоспособности региона как базовой составляющей региональной идентичности // Сибирская финансовая школа. 2009. № 2. C. 20-23. 
16. Данько Т.П., Зарова Е.В. Методика оценки конкурентоспособности региона на основе коэффициента делового позиционирования бизнеса // Экономические науки. 2015. № 126. С. 105-112.

17. Кагарманова А.И. Совершенствование методики оценки конкурентоспособности региона // Фундаментальные исследования. 2016. № 3-3. С. 579-583.

\section{Информация о конфликте интересов}

Мы, авторы данной статьи, со всей ответственностью заявляем о частичном и полном отсутствии фактического или потенциального конфликта интересов с какой бы то ни было третьей стороной, который может возникнуть вследствие публикации данной статьи. Настоящее заявление относится к проведению научной работы, сбору и обработке данных, написанию и подготовке статьи, принятию решения о публикации рукописи. 
pISSN 2073-1477

eISSN 2311-8733

\title{
A METHODOLOGY FOR THE INTEGRATED ASSESSMENT OF THE DEVELOPMENT OF COMPETITION IN THE REGION
}

\section{Viktoriya V. BOBROVA, ${ }^{\mathrm{a}, \bullet}$, Igor' N. KORABEINIKOV ${ }^{\mathrm{b}}$, Ol'ga I. BANTIKOVA}

${ }^{a}$ Orenburg State University, Orenburg, Russian Federation

bobrova1971@mail.ru

${ }^{\mathrm{b}}$ Orenburg State University, Orenburg, Russian Federation

igor.korabeynikov@mail.ru

${ }^{c}$ Orenburg State University, Orenburg, Russian Federation

bantikova777@mail.ru

- Corresponding author

\section{Article history:}

Received 2 June 2017

Received in revised form

16 June 2017

Accepted 26 June 2017

Available online

15 September 2017

JEL classification: D41, L16, L19, R52, R58

Keywords: specifics, competitive development, socially significant and priority markets, factors

\begin{abstract}
Importance The paper considers the economic, investment, organizational, and other relations arising in the process of competition development in socially important and priority markets of the region.

Objectives The paper aims to identify the regional peculiarities in the competitive development of socially important and priority markets.

Methods The leading method of the work is a sociological study and quantification of the obtained results.

Results We propose a methodology for sociological evaluation research of the socially important markets by the business community. It is based on an integrated assessment of indicators in assessing the competition and competitive environment.

Conclusions and Relevance On the basis of the proposed methods, we highlight the peculiarities and factors of the competitive development of socially important and priority markets at the regional level. We show that regional characteristics of the market include certain problems in relations with natural monopolies and the lack of awareness of the business community. The article materials can be useful to professionals who are involved in the competitive development of mesoeconomic market systems.
\end{abstract}

(C) Publishing house FINANCE and CREDIT, 2017

Please cite this article as: Bobrova V.V., Korabeinikov I.N., Bantikova O.I. A methodology for the integrated assessment of the development of competition in the region. Regional Economics: Theory and Practice, 2017, vol. 15, iss. 9, pp. $1598-1614$.

https://doi.org/10.24891/re.15.9.1598

\section{Acknowledgments}

We express our gratitude and appreciation to Elena S. ZDOROVA, Ph.D. in Economics, Deputy Minister, Head of Economy and Macroeconomic Forecasting Department, for the advice and valuable comments during the work on this article.

This article was supported by regional grant, Agreement No. 30 of June 30, 2016.

\section{References}

1. Zav'yalova T.A. [Competitiveness of economy: from assessment to methods]. Kreativnaya ekonomika = Journal of Creative Economy, 2011, no. 9, pp. 10-15.

URL: https://cyberleninka.ru/article/n/konkurentosposobnost-ekonomiki-ot-otsenki-kmetodike (In Russ.)

2. Marshall A. Printsipy politicheskoi ekonomii [Principles of Economics]. Moscow, Progress Publ., 1983, 416 p.

3. Fatkhutdinov R.A. [Competitiveness and competition management: the new theory concept]. Sovremennaya konkurentsiya $=$ Journal of Modern Competition, 2007, no. 1, pp. 73-86. (In Russ.) 
4. Kharlamov V.I. [Multidimensional treatment of the category "competition"]. Vestnik Belgorodskogo universiteta kooperatsii, ekonomiki i prava $=$ Herald of Belgorod University of Cooperation, Economics and Law, 2005, no. 5, pp. 125-129. (In Russ.)

5. Porter M.E. Mezhdunarodnaya konkurentsiya: konkretnye preimushchestva stran [The Competitive Advantage of Nations]. Moscow, Mezhdunarodnye otnosheniya Publ., 1993, 896 p.

6. Bogomolova I.V., Mashentsova L.S. [The technique of assessing the cities' competitiveness by means of quantitative and qualitative parameters]. Vestnik Volgogradskogo gosudarstvennogo universiteta. Seriya 3. Ekonomika. Ekologiya = Science Journal of VolSU. Global Economic System, 2015, no. 3, pp. 20-26. (In Russ.) doi: $10.15688 /$ jvolsu3.2015.3.2

7. Grineva N.A. [Estimation procedure of regional competitiveness]. Nauchnye vedomosti BelGU. Seriya Ekonomika. Informatika = Belgorod State University Scientific Bulletin. History, Political Science, Economics, Information Technologies, 2010, vol. 13, iss. 15/1, pp. 15-22. URL: https://www.bsu.edu.ru/upload/iblock/c6f/r\%2013_84_vip_15_1.pdf (In Russ.)

8. Dugina E.L., Bitueva D.V. et al. Formirovanie i razvitie konkurentosposobnoi sistemy otraslevykh rynkov regiona: kollektivnaya monografiya [Formation and development of a competitive industry markets in the region: a collective monograph]. Ulan-Ude, ESSUTM Publ., 2015, 216 p.

9. Smirnov V.V. [Technique of the estimation of competitiveness of region: the theory and practice]. Vestnik Chuvashskogo universiteta, 2008, no. 3, pp. 470-480. (In Russ.)

10. Khudeeva V.V. [On the approaches to the competitiveness estimation of the region in terms of modernization of federal politics of the regional development: the assessment method]. Vestnik Chelyabinskogo gosudarstvennogo universiteta $=$ Herald of Chelyabinsk State University, 2011, no. 32, pp. 60-64. (In Russ.)

11. Pashnanov E.L. [Method of assessment of regional socio-economic systems]. Upravlenie ekonomicheskimi sistemami: elektronnyi nauchnyi zhurnal, 2012, no. 6, p. 14. (In Russ.) URL: https://cyberleninka.ru/article/n/metodika-otsenki-razvitiya-regionalnyh-sotsialnoekonomicheskih-sistem-1

12. Prokushev E.F., Grineva N.A. [Review of modern domestic methods of regional competitiveness assessment and necessity of their development with regard of labor resources]. Vestnik Belgorodskogo universiteta kooperatsii, ekonomiki i prava $=$ Herald of Belgorod University of Cooperation, Economics and Law, 2015, no. 3, pp. 86-95. (In Russ.)

13. Sopova E.V., Shcherbinina L.Yu. [A methodological review on competition level assessment in the market]. Voprosy ekonomiki i upravleniya, 2016, no. 3-1, pp. 47-49. (In Russ.)

14. Azoev G.L. Konkurentsiya: analiz, strategiya i praktika: monografiya [Competition: analysis, strategy and practice: a monograph]. Moscow, Tsentr ekonomiki i marketinga Publ., 1996, 208 p.

15. Yalina N.V. [Methodology for assessing the competitiveness of the region as a basic component of regional identity]. Sibirskaya finansovaya shkola = Siberian Financial School, 2009, no. 2, pp. 20-23. (In Russ.) 
16. Dan'ko T.P., Zarova E.V. [Methods of assessing the competitiveness of the region based on the ratio of business positioning business]. Ekonomicheskie nauki = Economic Sciences, 2015, no. 126, pp. 105-112. URL: http://ecsn.ru/files/pdf/201505/201505_105.pdf (In Russ.)

17. Kagarmanova A.I. [Improvement of the methodology for assessing the competitiveness of the region]. Fundamental'nye issledovaniya = Fundamental Research, 2016, vol. 3, iss. 3, pp. 579-583. URL: http://fundamental-research.ru/en/article/view?id=40102 (In Russ.)

\section{Conflict-of-interest notification}

We, the authors of this article, bindingly and explicitly declare of the partial and total lack of actual or potential conflict of interest with any other third party whatsoever, which may arise as a result of the publication of this article. This statement relates to the study, data collection and interpretation, writing and preparation of the article, and the decision to submit the manuscript for publication. 